\title{
The prognostic impact of the neutrophil-to- lymphocyte ratio in patients with small-cell lung cancer
}

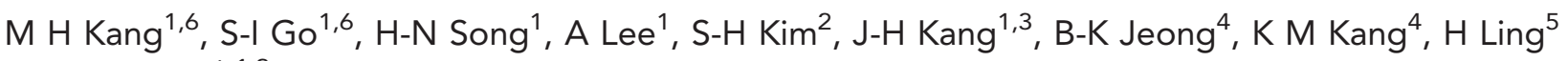 \\ and G-W Lee ${ }^{*}, 1,3$
}

${ }^{1}$ Division of Hematology-Oncology, Department of Internal Medicine, Gyeongsang National University Hospital Gyeongsang National University School of Medicine, Jinju, Republic of Korea; ${ }^{2}$ Division of Hematology and Medical Oncology, Department of Internal Medicine, Samsung Changwon Hospital, Sungkyunkwan University School of Medicine, Changwon, Republic of Korea; ${ }^{3}$ Gyeongsang Institute of Health Sciences, Jinju, Republic of Korea; ${ }^{4}$ Department of Radiation Oncology, Gyeongsang National University Hospital Gyeongsang National University School of Medicine, Jinju, Republic of Korea and ${ }^{5}$ Department of Experimental Therapeutics, The University of Texas MD Anderson Cancer Center, Houston, TX, USA

Background: The neutrophil-to-lymphocyte ratio (NLR) and platelet-to-lymphocyte ratio (PLR) are prognostic factors for various types of cancer. In this study, we assessed the association of NLR and PLR with the prognosis of small-cell lung cancer (SCLC) in patients who received the standard treatment.

Methods: We retrospectively reviewed patients who were diagnosed with SCLC and treated with platinum-based chemotherapy between July 2006 and October 2013 in Gyeongsang National University Hospital Regional Cancer Center and Changwon Samsung Hospital.

Results: In total, 187 patients were evaluated. Compared with low NLR $(<4)$, high NLR $(\geqslant 4)$ at diagnosis was associated with poor performance status, advanced stage, and lower response rate. Median overall survival (OS) and progression-free survival (PFS) were worse in the high-NLR group (high vs low, 11.17 vs 9.20 months, $P=0.019$ and 6.90 vs 5.49 months, $P=0.005$, respectively). In contrast, PLR at diagnosis was not associated with OS or PFS ( $P=0.467$ and $P=0.205$, respectively). In multivariate analysis, stage, lactate dehydrogenase, and NLR at diagnosis were independent prognostic factors for OS and PFS.

Conclusions: NLR is easily measurable and reflects the SCLC prognosis. A future prospective study is warranted to confirm our results.

Small-cell lung cancer (SCLC) accounts for $15-20 \%$ of all lung cancers and has an extremely aggressive nature with a poor prognosis (Buccheri and Ferrigno, 2004). Without treatment, the median survival time is $2-4$ months (Hayat et al, 2007).

Several clinical markers are related to prognosis in patients with SCLC. Stage is the most important predictor of survival in SCLC (Seifter and Ihde, 1988; Sagman et al, 1991; Buccheri and Ferrigno, 2004). The initial lactate dehydrogenase (LDH) level can indicate a high tumour burden and poor prognosis (Gronowitz et al, 1990; Buccheri and Ferrigno, 2004). Concurrent chemoradiotherapy (CCRT) in limited disease (LD) and prophylactic cranial irradiation (PCI) after complete response have improved the survival time of SCLC patients (Murray et al, 1993; Auperin et al, 1999). Performance status (PS) has been used traditionally to predict the outcome of patients with SCLC (Bremnes et al, 2003; Buccheri and Ferrigno, 2004). Gender, age,

${ }^{*}$ Correspondence: Professor G-W Lee; E-mail: brightree24@gmail.com
${ }^{6}$ These authors contributed equally to this work.

Received 13 February 2014; revised 24 April 2014; accepted 12 May 2014; published online 12 June 2014

(c) 2014 Cancer Research UK. All rights reserved 0007-0920/14 
and body weight loss are also prognostic factors (Spiegelman et al, 1989; Paesmans et al, 2000; Bremnes et al, 2003). In addition to these clinical markers, many investigators have suggested that laboratory markers, such as neuron-specific enolase, carcinoembryonic antigen, cytokeratin fragment 19 (CYFRA 21-1), haemoglobin, albumin, alkaline phosphatase, and white blood cell count could be of prognostic value (Albain et al, 1990; Gronowitz et al, 1990; Sagman et al, 1991; Bremnes et al, 2003). However, the optimum prognostic factor for SCLC remains controversial.

The systemic inflammatory response was shown to be associated with a poor prognosis in various solid tumours. Several inflammatory markers, such as C-reactive protein (CRP), Glasgow Prognostic Score, neutrophil-to-lymphocyte ratio (NLR), and platelet-to-lymphocyte ratio (PLR) have been evaluated in various types of cancer (Crumley et al, 2006; Kim et al, 2009; Kishi et al, 2009; Smith et al, 2009; Chua et al, 2011; Li et al, 2013; Stotz et al, 2014). Recently, tumour-associated neutrophils (TANs), which are distinct from naive neutrophils, were shown to be involved in tumour biology. Tumour cells themselves can recruit neutrophils into the tumour using specific chemokines (Bellocq et al, 1998; De Larco et al, 2004; Keane et al, 2004) and T cells (Stoppacciaro et al, 1993). TANs exert protumourigenic effects (Fridlender et al, 2009), including tumour initiation by genotoxic reactive oxygen species (Gungor et al, 2010), anti-apoptosis and angiogenesis by matrix metalloproteinase-9 (Acuff et al, 2006; Kuang et al, 2011), tumour growth, invasion and metastasis via neutrophil elastase (Sun and Yang, 2004; Houghton et al, 2010) and suppression of the adaptive immune system (Fridlender et al, 2009). Therefore, NLR might be considered a surrogate marker for TANs, and is readily available and cost-effective. Several reports have suggested the prognostic value of NLR in colorectal cancer, gastric cancer, non-small-cell lung cancer, soft-tissue sarcoma, and pancreatic cancer (Kim et al, 2009; Kishi et al, 2009; Smith et al, 2009; Cedres et al, 2012; Lee et al, 2013; Stotz et al, 2013; Szkandera et al, 2013). Because platelet activation is stimulated by proinflammatory cytokines and participates in neutrophil recruitment (Ghasemzadeh and Hosseini, 2013), PLR has also been evaluated as an inflammatory marker; high PLR has been reported to be a risk factor for poor survival in pancreatic and colorectal cancers (Smith et al, 2009; Kwon et al, 2012). Although high CRP was reportedly related to poor survival in a retrospective study (Hong et al, 2012), the prognostic value of inflammatory markers, including NLR and PLR, is not well understood in SCLC.

We hypothesised that inflammation is associated with the SCLC prognosis and that NLR or PLR may be good indicators of the inflammatory process. Therefore, in this retrospective study, we evaluated the association of NLR and PLR with the prognosis in SCLC patients who underwent the standard treatment.

\section{MATERIALS AND METHODS}

Study population. We retrospectively reviewed all patients diagnosed with SCLC between July 2006 and October 2013 in Gyeongsang National University Hospital Regional Cancer Center and Changwon Samsung Hospital. Histologically confirmed cases were included in the study. All patients received combination chemotherapy based on platinum agents such as cisplatin or carboplatin as first-line treatment for at least one cycle. Patients who received non-platinum-based chemotherapy only or who did not receive chemotherapy were excluded from the study. This study was approved by the Institutional Review Board of each participating hospital.
Table 1. Baseline characteristics

\begin{tabular}{|l|c|}
\hline & Number of patients $(\%) \mathbf{n = 1 8 7}$ \\
\hline Age, years $(n=187)$ & $68($ range $43-84)$
\end{tabular}

$\operatorname{Sex}(n=187)$

\begin{tabular}{|l|r|}
\hline Male & $162(86.6)$
\end{tabular}

Female $25(13.4)$

Smoking at diagnosis $(n=187)$

\begin{tabular}{|l|r|}
\hline Never smoker & $15(8.0)$
\end{tabular}

\begin{tabular}{l|r} 
Current or ex-smoker & $172(92.0)$
\end{tabular}

ECOG PS at diagnosis $(n=187)$

\begin{tabular}{|r|r}
\hline $0-1$ & $163(87.2)$ \\
$2-3$ & $24(12.8)$ \\
\hline
\end{tabular}

$2-3$

$24(12.8)$

Stage $(n=187)$

\begin{tabular}{|l|l}
\hline Limited disease & $67(35.8)$
\end{tabular}

Extensive disease $\quad 120(64.2)$

LDH at initial diagnosis $(n=187)$

\begin{tabular}{|l|r|}
\hline Normal range & $72(38.5)$ \\
Abnormally elevated & $115(61.5)$
\end{tabular}

Chemotherapy regimen $(n=187)$

\begin{tabular}{|l|r|}
\hline Etoposide-based & $155(82.9)$
\end{tabular}

Irinotecan-based $\quad 32(17.1)$

Response for initial chemotherapy $(n=187)$

\begin{tabular}{l|c}
\hline Complete response & $14(7.5)$ \\
Partial response & $139(74.3)$ \\
Stable disease & $8(4.3)$ \\
Progressive disease & $7(3.7)$ \\
Not evaluable & $19(10.2)$
\end{tabular}

Second-line chemotherapy $(n=125)$

\begin{tabular}{|l|r|}
\hline Yes & $75(60.0)$
\end{tabular}

No

$50(40.0)$

Thoracic radiotherapy $(n=187)$

\begin{tabular}{|r|r|}
\hline Yes & $62(33.2)$ \\
\hline$N o$
\end{tabular}

No

$125(66.8)$

Prophylactic cranial irradiation $(n=187)$

\begin{tabular}{|l|r}
\hline Yes & $47(25.1)$ \\
\hline
\end{tabular}

\begin{tabular}{l|r} 
No & $140(74.9)$
\end{tabular}

Abbreviations: $\mathrm{ECOG}=$ Eastern Cooperative Oncology Group; $\mathrm{LDH}=$ lactate dehydrogenase $\mathrm{PS}=$ performance status.

Clinical data collection. Baseline characteristics including demographics, smoking, PS, and medical history were collected using an electronic medical record system. Complete blood cell counts at diagnosis, after the first cycle of chemotherapy (immediately before the second cycle of chemotherapy), and at the time of progression were obtained. At diagnosis, LDH was also evaluated. Mean and peak standardised uptake values (SUVs) of initial positronemission tomography and computed tomography (PET-CT) were obtained if possible. Both NLR and PLR were recorded at diagnosis, after the first cycle of chemotherapy, and at the time of disease progression.

Statistical analysis. The optimal cutoff values for NLR and PLR were determined using time-dependent receiver operating curve 
Table 2. Change of NLR and PLR at diagnosis, after one cycle chemotherapy, and at progression

\begin{tabular}{|l|c|c|c|c|c|c|}
\hline Value & At diagnosis & $\begin{array}{c}\text { After one cycle } \\
\text { of chemotherapy }\end{array}$ & $\boldsymbol{P}$ & $\begin{array}{c}\text { After 1 cycle } \\
\text { of chemotherapy }\end{array}$ & At progression & $\boldsymbol{P}$ \\
\hline NLR, mean \pm s.d. & $3.78 \pm 3.13$ & $2.63 \pm 2.80$ & $<0.001$ & $2.63 \pm 2.80$ & $4.50 \pm 6.37$ & $<0.001$ \\
\hline PLR, mean \pm s.d. & $183.16 \pm 98.21$ & $173.16 \pm 119.93$ & 0.01 & $173.16 \pm 119.93$ & $181.69 \pm 143.11$ & 0.518 \\
\hline
\end{tabular}

Abbreviations: NLR = neutrophil-lymphocyte ratio; PLR=platelet-lymphocyte ratio; s.d. = standard deviation .

\section{Table 3. Clinical manifestations and laboratory parameters according to NLR at diagnosis}

\begin{tabular}{|c|c|c|c|}
\hline & $\begin{array}{c}\text { NLR }<4 \\
\text { Number of patients (\%) } n=128\end{array}$ & $\begin{array}{c}\text { NLR } \geqslant 4 \\
\text { Number of patients }(\%) n=59\end{array}$ & $P$ \\
\hline Age, years $(n=187)$ & 68 (range 43-84) & 68 (range 43-82) & 0.976 \\
\hline $\operatorname{Sex}(n=187)$ & & & 0.383 \\
\hline Male & $109(85.2)$ & $53(89.8)$ & \\
\hline Female & 19 (14.8) & $6(10.2)$ & \\
\hline Smoking at diagnosis $(n=187)$ & & & 0.671 \\
\hline Never smoker & $11(8.6)$ & $4(6.8)$ & \\
\hline Current or ex-smoker & $117(91.4)$ & 55 (93.2) & \\
\hline ECOG PS at diagnosis $(n=187)$ & & & $<0.001$ \\
\hline $0-1$ & $119(93.0)$ & $44(74.6)$ & \\
\hline $2-3$ & $9(7.0)$ & $15(25.4)$ & \\
\hline Stage $(n=187)$ & & & 0.001 \\
\hline Limited disease & $56(43.8)$ & $11(18.6)$ & \\
\hline Extensive disease & $72(56.3)$ & 48 (81.4) & \\
\hline Platelet, $\times 10^{9} / \mathrm{l}$, mean \pm s.d. $(n=187)$ & $267 \pm 109$ & $324 \pm 400$ & 0.484 \\
\hline PLR at diagnosis, mean \pm s.d. $(n=187)$ & $150.19 \pm 78.13$ & $254.69 \pm 99.79$ & $<0.001$ \\
\hline LDH at diagnosis $(n=187)$ & & & 0.579 \\
\hline Normal range & $51(39.8)$ & $21(33.6)$ & \\
\hline Abnormally elevated & $77(60.2)$ & $38(64.4)$ & \\
\hline Chemotherapy regimen $(n=187)$ & & & 0.225 \\
\hline Etoposide-based & $109(85.2)$ & $46(78.0)$ & \\
\hline Irinotecan-based & $19(14.8)$ & $13(22.0)$ & \\
\hline Response for initial chemotherapy $(n=187)$ & & & 0.037 \\
\hline Complete response & $11(8.6)$ & $3(5.1)$ & \\
\hline Partial response & $98(76.6)$ & $41(69.5)$ & \\
\hline Stable disease & $6(4.7)$ & $2(3.4)$ & \\
\hline Progressive disease & $6(4.7)$ & $1(1.7)$ & \\
\hline Not evaluable & $7(5.5)$ & $12(20.3)$ & \\
\hline Mean SUV at initial PET-CT, mean \pm s.d. $(n=164)$ & $7.15 \pm 2.43$ & $7.10 \pm 3.07$ & 0.341 \\
\hline Peak SUV at initial PET-CT, mean \pm s.d. $(n=164)$ & $9.71 \pm 3.14$ & $10.29 \pm 6.38$ & 0.188 \\
\hline Second-line chemotherapy $(n=125)$ & & & 0.379 \\
\hline Yes & 55 (62.5) & $20(54.1)$ & \\
\hline No & $33(37.5)$ & $17(45.9)$ & \\
\hline Thoracic radiotherapy $(n=187)$ & & & $<0.001$ \\
\hline Yes & $54(42.2)$ & $8(13.6)$ & \\
\hline No & $74(57.8)$ & $51(86.4)$ & \\
\hline Prophylactic cranial irradiation $(n=187)$ & & & 0.005 \\
\hline Yes & $40(31.2)$ & $7(11.9)$ & \\
\hline No & $88(68.8)$ & $52(88.1)$ & \\
\hline
\end{tabular}


(ROC) analysis. Time-dependent ROC analysis was performed using $\mathrm{R}$ software, version 3.03 (The $\mathrm{R}$ foundation for statistical computing, Vienna, Austria. http://www.r-project.org) and the 'timeROC' package (Adams et al, 2009; Blanche et al, 2013). The NLR was calculated from the differential counts by dividing the neutrophil number by the lymphocyte number. The NLR values were categorised into two groups: $<4$ and $\geqslant 4$. The PLR was calculated by dividing the platelet count by the lymphocyte count; a PLR $\geqslant 160$ was considered to be elevated.

Statistical analyses were performed using SPSS 21.0 for Windows software (SPSS Inc., Chicago, IL, USA). Continuous variables were expressed as means with standard deviation (s.d.) and range, and compared between the low- and high-NLR groups using the Mann-Whitney $U$-test or Wilcoxon signed-rank test. The categorical variables were presented as the numbers of patients and percentages and compared using the $\chi^{2}$ - or Fisher's exact test.

The overall survival (OS) was calculated from the time of diagnosis to the time of death. The progression-free survival (PFS) was defined as the period from the time of therapy initiation to the time of disease progression or death. Survival analyses were performed using the Kaplan-Meier method. Significant differences between groups were identified using the log-rank test. Multivariate analysis of survival was performed using the Cox proportional hazards model, and the associated $95 \%$ confidence interval was calculated. All tests were two-sided, and $P<0.05$ was considered to indicate statistical significance.
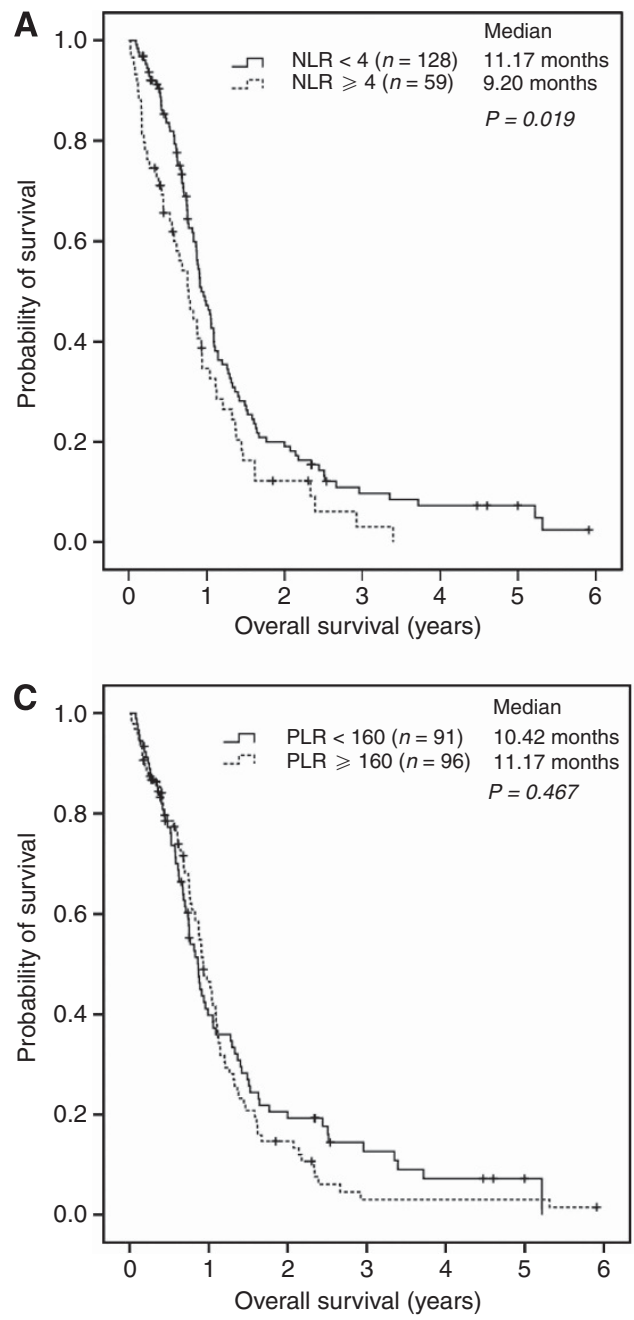

\section{RESULTS}

Patient characteristics. In total, 187 patients were enrolled in this study between July 2006 and October 2013. The median follow-up time was 40.28 months (range, $2.60-89.26$ months). The baseline characteristics of the patients are shown in Table 1 . The median age was 68 years (range, 43-84 years) and 162 patients (86.6\%) were male and $25(13.4 \%)$ were female. The majority of patients were current or ex-smokers $(n=172,92 \%)$. performance status was generally good, 163 patients $(87.2 \%)$ were Eastern Cooperative Oncology Group (ECOG) PS 0 or 1 . Only 67 patients (35.8\%) were $\mathrm{LD}$ and $120(64.2 \%)$ were $\mathrm{ED}$ at the time of diagnosis.

The most often used chemotherapeutic regimen was etoposidebased combination chemotherapy $(n=155,82.9 \%)$. Irinotecan $(n=32,17.1 \%)$ was also used as a first-line combination agent in place of etoposide. Clinical response was evaluated after two or three cycles of chemotherapy. Among the 187 patients, 153 (81.8\%) obtained at least partial response; the disease control rate was $86.1 \%$. Of the 125 patients with disease progression, 75 (60.0\%) received second-line chemotherapy. In LD, 62 of 67 patients (92.5\%) were treated with thoracic radiotherapy (RT). Forty-seven of 187 patients (25.1\%) received PCI after the first-line chemotherapy.

NLR and PLR according to disease and treatment status. Mean NLR and PLR values were compared according to disease and
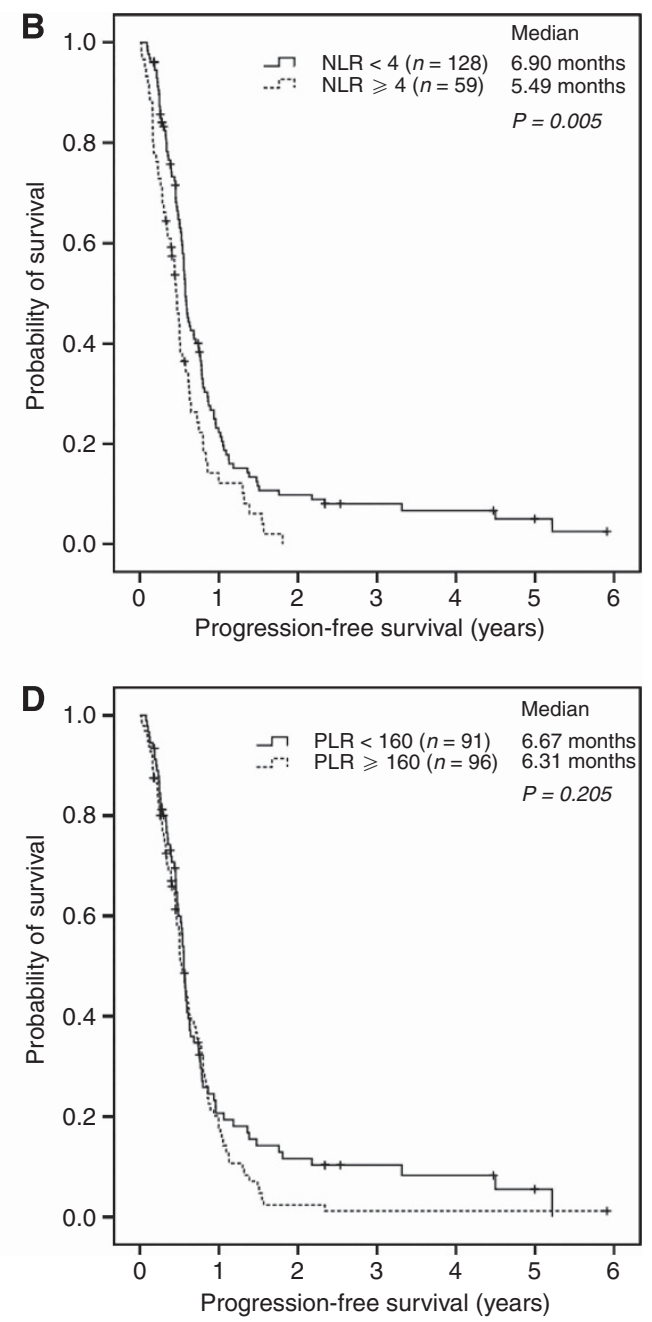

Figure 1. Kaplan-Meier curves for survival according to NLR and PLR at diagnosis. (A) OS stratified by NLR. (B) PFS stratified by NLR. (C) OS stratified by PLR. (D) PFS stratified by PLR. Abbreviations: NLR= neutrophil-to-lymphocyte ratio; OS =overall survival; PFS = progression-free survival; PLR = platelet-to-lymphocyte ratio. 
treatment status (Table 2). Mean \pm s.d. NLR was $3.78 \pm 3.13$ at diagnosis, and decreased significantly to $2.63 \pm 2.80$ after one cycle of chemotherapy $(P<0.001)$. Compared with after one cycle of chemotherapy, mean \pm s.d. NLR increased significantly to $4.50 \pm 6.37$ at disease progression $(P<0.001)$. Mean \pm s.d. PLR after one cycle of chemotherapy also decreased significantly from $183.16 \pm 98.21$ at diagnosis to $173.16 \pm 119.93(P=0.01)$. However, there was no significant difference in mean \pm s.d. PLR at disease progression ( $v s$ after one cycle of chemotherapy, $P=0.518$ ).

Factors associated with NLR. Clinical and laboratory factors according to NLR group are shown in Table 3. Age, gender, smoking status, first-line chemotherapy regimen, mean or peak SUV at initial PET-CT, and LDH were similar between the groups. However, PS was significantly worse (ECOG PS 2-3 in low $v$ s high, $7.0 \%$ vs $25.4 \%$, respectively, $P<0.001)$ and clinical stage was relatively more advanced (ED in low vs high, $56.3 \%$ vs $81.4 \%$, respectively, $P=0.001$ ) in the high-NLR group compared with the low-NLR group. Additionally, more patients received thoracic RT (low vs high, $42.2 \%$ vs $13.6 \%$, respectively, $P<0.001$ ) and PCI (low vs high, $31.2 \%$ vs $11.9 \%$, respectively, $P=0.004)$ in the low-NLR group. Although platelet count did not show a significant difference $(P=0.484)$, the mean PLR at diagnosis was higher in the high-NLR group (low vs high, 150.19 vs 254.69, respectively, $P<0.001$ )

Additionally, the rate of objective response (complete and partial response) to first-line chemotherapy was significantly lower in the high-NLR group than in the low-NLR group (low vs high, $85.2 \%$ vs $74.6 \%$, respectively, $P=0.037$ ).

Association of NLR and PLR with survival. In total, median OS was 10.84 months and median PFS was 6.67 months. NLR and PLR levels at diagnosis had different impacts on survival (Figure 1). High NLR at diagnosis was associated with worse OS $(\mathrm{NLR}<4$ vs $\mathrm{NLR} \geqslant 4$, median OS 11.17 vs 9.20 months, respectively, $P=0.019$ ) and PFS $(\mathrm{NLR}<4$ vs NLR $\geqslant 4$, median PFS 6.90 vs 5.49 months, respectively, $P=0.005)$. In contrast, PLR at diagnosis was not associated with OS (PLR $<160$ vs PLR $\geqslant 160$, median OS 10.42 vs 11.17 months, respectively, $P=0.467)$ and PFS (PLR $<160$ vs $\mathrm{PLR} \geqslant 160$, median PFS 6.67 vs 6.31 months, respectively, $P=0.205)$.

Patients with a high NLR at both diagnosis and after one cycle of chemotherapy showed worse OS and PFS than patients with low or high NLR at diagnosis and low NLR after one cycle of chemotherapy (Figure $2 \mathrm{~A}, P<0.001$ and $P=0.007$, respectively). In addition, patients with a high NLR at disease progression and a
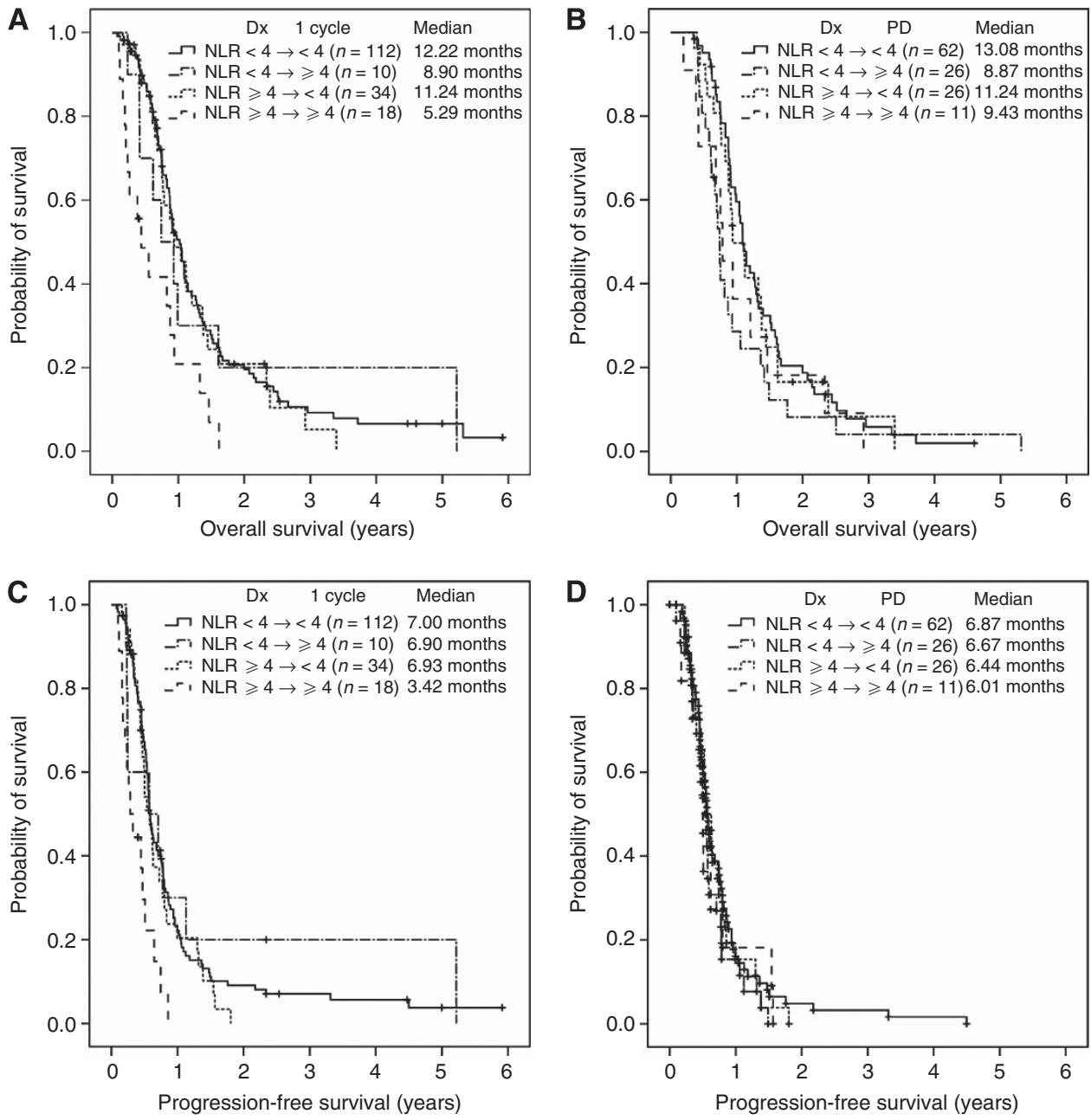

Figure 2. Kaplan-Meier curves for survival according to NLR and treatment course. (A) OS and (C) PFS stratified by NLR at diagnosis and after one cycle of chemotherapy. Patients with high NLR both at diagnosis and after one cycle of chemotherapy showed worse OS and PFS than patients with low or high NLR at diagnosis and low NLR after one cycle of chemotherapy $(P<0.001$ and $P=0.007$, respectively). (B) OS and (D) PFS stratified by NLR at diagnosis and at disease progression. Among patients with low NLR at diagnosis, patients with high NLR at disease progression showed worse OS than patients with low NLR at disease progression $(P=0.033)$. Abbreviations: $D x=$ at diagnosis; NLR $=$ neutrophil-tolymphocyte ratio; $O S=$ overall survival; $P D=$ at disease progression; PFS = progression-free survival; 1 cycle =after 1 cycle of chemotherapy. 
low NLR at diagnosis had a worse OS than patients with low NLR both at diagnosis and disease progression $(P=0.033$, Figure $2 \mathrm{~B})$. Similarly, PFS was worse in patients with a high NLR both at diagnosis and after one cycle of chemotherapy compared with those with low NLR after one cycle of chemotherapy $(P<0.001 \mathrm{vs}$ an initial low NLR, and $P=0.004$ vs initially high NLR; Figure 2C). However, there was no significant difference in the PFS between changes in NLR according to progression time (Figure 2D).
According to clinical stage and disease course, NLR had a slightly different impact on survival. At the time of diagnosis, the ED survival curve showed significant differences according to the NLR $(P=0.018)$ compared with LD, which consisted of only 11 high-NLR patients $(P=0.946$; Figure $3 \mathrm{~A}$ and $\mathrm{B})$. This survival curve pattern was statistically more significant in ED patients after one cycle of chemotherapy $(P=0.001)$, whereas no significant differences according to NLR status were observed in LD patients
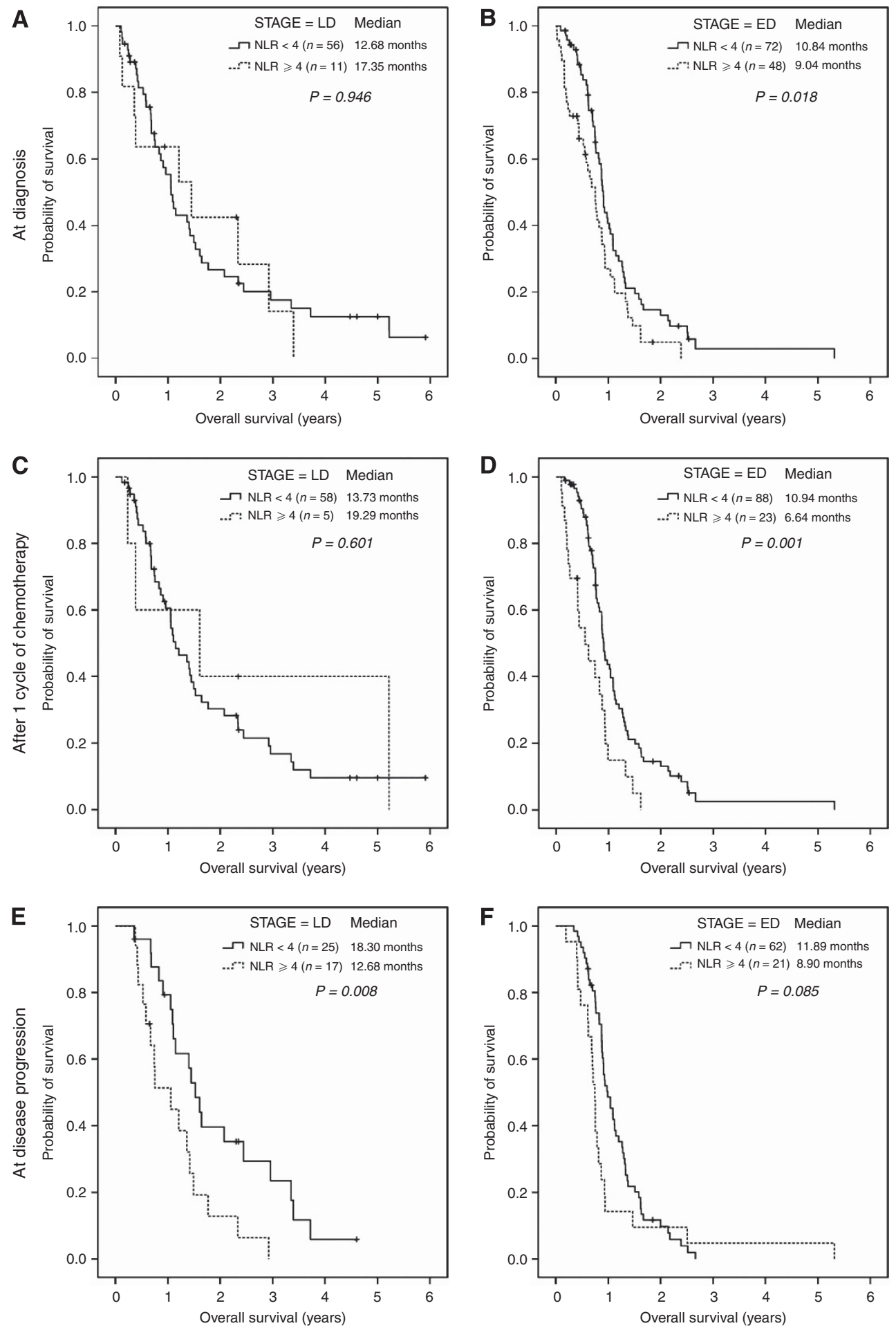

Figure 3. Kaplan-Meier curves for OS according to NLR, stage and treatment course. OS stratified according to the NLR at diagnosis in (A) LD and (B) ED patients. OS stratified according to the NLR after one cycle of chemotherapy in (C) LD and (D) ED patients. OS stratified according to the NLR at disease progression in $(E) L D$ and $(F) E D$ patients. Abbreviations: $E D=$ extensive disease; $L D=$ limited disease; NLR=neutrophil-tolymphocyte ratio; $\mathrm{OS}=$ overall survival. 
after one cycle of chemotherapy $(P=0.601$; Figure $3 \mathrm{C}$ and D). At the time of disease progression, LD patients showed a significant difference in survival according to the NLR $(P=0.008)$. However, no statistical significance was found in ED patients according to the NLR $(P=0.085$; Figure $3 \mathrm{E}$ and $\mathrm{F})$.

In subgroup analysis of PLR according to clinical stage and disease course, PLR and OS were not correlated, except when survival of LD patients was compared using the PLR level at disease progression (PLR $<160$ vs $\mathrm{PLR} \geqslant 160$, median OS 24.87 vs 13.73 months, respectively, $P=0.022$ ).

Univariate analysis was performed for clinical and laboratory factors. Factors associated with poor OS were ED, elevated LDH, and high NLR at any time. Factors related to poor PFS were ED, elevated LDH, irinotecan-based first-line regimen, and high NLR at diagnosis. Stage, LDH, NLR, and PLR at diagnosis were included in the multivariate analysis (Table 4). ED, elevated $\mathrm{LDH}$, and high NLR, but not high PLR, at diagnosis were independent prognostic factors for OS and PFS.

\section{DISCUSSION}

In this study we reviewed the prognostic significance of NLR and PLR with other clinical factors in SCLC patients. PLR had little influence on survival; however, ED, elevated LDH, and high NLR at diagnosis were associated with poor OS and PFS in SCLC patients who underwent first-line chemotherapy.

The high-NLR group included significantly more ED patients than the low-NLR group in this study. Therefore, worse survival in the high-NLR group might be explained in part by selection bias, because the low-NLR group included more LD patients, who had a better prognosis than ED patients and who received additional curative treatments such as CCRT and PCI. However, several findings suggest that NLR was an independent prognostic marker regardless of stage. For OS and PFS, NLR was demonstrated as a prognostic factor via multivariate analysis including stage and LDH. In addition, subgroup analysis according to stage showed

Table 4. Multivarate analysis for overall survival and progression-free survival

\begin{tabular}{|c|c|c|c|c|c|c|}
\hline & \multicolumn{3}{|c|}{ Overall survival } & \multicolumn{3}{|c|}{ Progression-free survival } \\
\hline & HR & $95 \% \mathrm{Cl}$ & $P$ & HR & $95 \% \mathrm{Cl}$ & $P$ \\
\hline \multicolumn{7}{|l|}{ Stage } \\
\hline LD & Reference & & & Reference & & \\
\hline ED & 1.546 & $1.072-2.230$ & 0.020 & 1.700 & $1.193-2.422$ & 0.003 \\
\hline \multicolumn{7}{|l|}{ LDH } \\
\hline Normal & Reference & & & Reference & & \\
\hline Elevated & 1.507 & $1.078-2.107$ & 0.016 & 1.658 & $1.199-2.294$ & 0.002 \\
\hline \multicolumn{7}{|c|}{ NLR at diagnosis } \\
\hline$<4$ & Reference & & & Reference & & \\
\hline$\geqslant 4$ & 1.465 & $1.012-2.119$ & 0.043 & 1.474 & $1.033-2.105$ & 0.032 \\
\hline \multicolumn{7}{|c|}{ PLR at diagnosis } \\
\hline $\begin{array}{l}<160 \\
\geqslant 160\end{array}$ & $\begin{array}{c}\text { Reference } \\
0.896\end{array}$ & $0.628-1.280$ & 0.547 & $\begin{array}{c}\text { Reference } \\
0.961\end{array}$ & $0.685-1.347$ & 0.816 \\
\hline $\begin{array}{l}\text { Abbreviatio } \\
\text { lactate de } \\
\text { ratio. }\end{array}$ & $\begin{array}{l}\mathrm{Cl}=\text { confid } \\
\text { drogenase; }\end{array}$ & $\begin{array}{l}\text { ence interval; } E D \\
N L R=\text { neutroph }\end{array}$ & $\begin{array}{l}=\text { exter } \\
\text { lymph }\end{array}$ & $\begin{array}{l}\text { sive disease; } \\
\text { cyte ratio; }\end{array}$ & $\begin{array}{l}-\mathrm{HR}=\text { hazard ratic } \\
\mathrm{LR}=\text { platelet-lym }\end{array}$ & $\begin{array}{l}\text {; } \mathrm{LDH}= \\
\text { aphocyte }\end{array}$ \\
\hline
\end{tabular}

that OS in the high-NLR group was significantly shorter than in the low-NLR group in ED patients. Although no significant difference in OS in LD patients was found, the numbers of LD patients with a high NLR at diagnosis $(n=11)$ and after one cycle of chemotherapy $(n=5)$ were too small for statistically significant evaluation, and the high-NLR group at disease progression showed significantly decreased OS in LD patients $(n=17)$. Furthermore, the high-NLR group had worse PS at diagnosis than the low-NLR group. For these reasons, we suggest that NLR is an independent prognostic factor for survival in SCLC patients.

As shown in Tables 2 and 3, the NLR level changed with the disease and treatment course, and the response rate was lower in patients with high NLR at diagnosis. The NLR level decreased significantly even after only one cycle of chemotherapy. Given that the treatment response was over $80 \%$ in this study, a decrease in the tumour burden may be achieved in most patients after one cycle of chemotherapy. At disease progression, the NLR level increased significantly compared with after one cycle of chemotherapy. These results imply that the NLR may reflect tumour burden and help in assessing the treatment response and monitoring recurrence or progression of SCLC. The clinical importance of the NLR is supported by our findings that the subgroup of patients who failed to achieve a low NLR after one cycle of chemotherapy and patients with a high NLR at disease progression showed poor survival.

A high NLR indicates an increased neutrophil count and/or a decreased lymphocyte count, as well as relative lymphopaenia. Lymphocytes have a crucial role in tumour defence by inducing cytotoxic cell death and inhibiting tumour cell proliferation and migration (Coussens and Werb, 2002; Mantovani et al, 2008). In contrast, large numbers of neutrophils affect the cytolytic activity of lymphocytes or natural killer cells and could negatively affect tumour growth (Pillay et al, 2012). In addition to the TANs described above, neutrophil extracellular traps (NETs), which are fibres composed of chromatin and neutrophil proteins (Berger-Achituv et al, 2013), are known to be associated with cancer. TANs are more prone to NETs than their normal counterparts (Berger-Achituv et al, 2013; Demers and Wagner, 2013). An experimental study demonstrated that widespread deposition of NETs induced by sepsis sequesters circulating tumour cells and promotes metastasis (Cools-Lartigue et al, 2013). NETs may protect circulating tumour cells by adhering to them and recruiting platelets (Demers and Wagner, 2013). These theoretical considerations support the role of NLR, reflecting the extent of neutrophilia in malignancy.

NLR is an easily measurable and repeatable parameter and thus clinically useful. However, several problems exist. NLR may occasionally not be a tumour-specific marker because other inflammatory conditions and steroid treatments could be confounding factors. Some authors have suggested that NLR should be assessed together with other inflammatory markers such as CRP (Nakamura et al, 2013; Yalcinkaya et al, 2013). In addition, numerous articles have reported on NLR using different cutoff levels that require validation. In a study that showed a significant correlation between the NLR and survival in patients with stage IV gastric cancer, the authors used a NLR level of 2.5 and median survival was significantly longer in the group with a low-NLR level (Yamanaka et al, 2007). Other studies reported a correlation between NLR and survival, using various cutoff values (Yamanaka et al, 2007; Kishi et al, 2009; Chua et al, 2011; Stotz et al, 2013).

This study had several limitations. First, the sample size was relatively small, which limits generalising our findings. Second, as with all retrospective studies, there are several limitations inherent to its design, including the retrospective data collection. Nevertheless, to our knowledge, this is the first study to suggest the usefulness of NLR and investigate the prognostic role of NLR in SCLC patients. 
In conclusion, NLR at the time of diagnosis is a readily available and effective measurement that reflects the prognosis in SCLC patients. NLR determination during treatment and monitoring may help in assessing the treatment response and predicting recurrence. Further prospective studies are needed to evaluate cutoff values and confirm our results.

\section{REFERENCES}

Acuff HB, Carter KJ, Fingleton B, Gorden DL, Matrisian LM (2006) Matrix metalloproteinase-9 from bone marrow-derived cells contributes to survival but not growth of tumor cells in the lung microenvironment. Cancer Res 66: 259-266.

Adams H, Tzankov A, Lugli A, Zlobec I (2009) New time-dependent approach to analyse the prognostic significance of immunohistochemical biomarkers in colon cancer and diffuse large B-cell lymphoma. J Clin Pathol 62: 986-997.

Albain KS, Crowley JJ, LeBlanc M, Livingston RB (1990) Determinants of improved outcome in small-cell lung cancer: an analysis of the 2,580-patient Southwest Oncology Group data base. J Clin Oncol 8: $1563-1574$.

Auperin A, Arriagada R, Pignon JP, Le Pechoux C, Gregor A, Stephens RJ, Kristjansen PE, Johnson BE, Ueoka H, Wagner H, Aisner J (1999) Prophylactic cranial irradiation for patients with small-cell lung cancer in complete remission. Prophylactic Cranial Irradiation Overview Collaborative Group. N Engl J Med 341: 476-484.

Bellocq A, Antoine M, Flahault A, Philippe C, Crestani B, Bernaudin JF, Mayaud C, Milleron B, Baud L, Cadranel J (1998) Neutrophil alveolitis in bronchioloalveolar carcinoma: induction by tumor-derived interleukin- 8 and relation to clinical outcome. Am J Pathol 152: 83-92.

Berger-Achituv S, Brinkmann V, Abed UA, Kuhn LI, Ben-Ezra J, Elhasid R, Zychlinsky A (2013) A proposed role for neutrophil extracellular traps in cancer immunoediting. Front Immunol 4: 48.

Blanche P, Dartigues JF, Jacqmin-Gadda H (2013) Estimating and comparing time-dependent areas under receiver operating characteristic curves for censored event times with competing risks. Stat Med 32: 5381-5397.

Bremnes RM, Sundstrom S, Aasebo U, Kaasa S, Hatlevoll R, Aamdal S (2003) The value of prognostic factors in small cell lung cancer: results from a randomised multicenter study with minimum 5 year follow-up. Lung Cancer 39: 303-313.

Buccheri G, Ferrigno D (2004) Prognostic factors of small cell lung cancer. Hematol Oncol Clin North Am 18: 445-460.

Cedres S, Torrejon D, Martinez A, Martinez P, Navarro A, Zamora E, Mulet-Margalef N, Felip E (2012) Neutrophil to lymphocyte ratio (NLR) as an indicator of poor prognosis in stage IV non-small cell lung cancer. Clin Transl Oncol 14: 864-869.

Chua W, Charles KA, Baracos VE, Clarke SJ (2011) Neutrophil/lymphocyte ratio predicts chemotherapy outcomes in patients with advanced colorectal cancer. Br J Cancer 104: 1288-1295.

Cools-Lartigue J, Spicer J, McDonald B, Gowing S, Chow S, Giannias B, Bourdeau F, Kubes P, Ferri L (2013) Neutrophil extracellular traps sequester circulating tumor cells and promote metastasis. J Clin Invest; e-pub ahead of print 1 July 2013; doi:10.1172/JCI67484.

Coussens LM, Werb Z (2002) Inflammation and cancer. Nature 420: 860-867.

Crumley AB, McMillan DC, McKernan M, McDonald AC, Stuart RC (2006) Evaluation of an inflammation-based prognostic score in patients with inoperable gastro-oesophageal cancer. Br J Cancer 94: 637-641.

De Larco JE, Wuertz BR, Furcht LT (2004) The potential role of neutrophils in promoting the metastatic phenotype of tumors releasing interleukin-8. Clin Cancer Res 10: 4895-4900.

Demers M, Wagner DD (2013) Neutrophil extracellular traps: a new link to cancer-associated thrombosis and potential implications for tumor progression. Oncoimmunology 2: e22946.

Fridlender ZG, Sun J, Kim S, Kapoor V, Cheng G, Ling L, Worthen GS, Albelda SM (2009) Polarization of tumor-associated neutrophil phenotype by TGF-beta: "N1" versus "N2" TAN. Cancer Cell 16: 183-194.

Ghasemzadeh M, Hosseini E (2013) Platelet-leukocyte crosstalk: linking proinflammatory responses to procoagulant state. Thromb Res 131: 191-197.

Gronowitz JS, Bergstrom R, Nou E, Pahlman S, Brodin O, Nilsson S, Kallander CF (1990) Clinical and serologic markers of stage and prognosis in small cell lung cancer. A multivariate analysis. Cancer 66: 722-732.
Gungor N, Knaapen AM, Munnia A, Peluso M, Haenen GR, Chiu RK, Godschalk RW, van Schooten FJ (2010) Genotoxic effects of neutrophils and hypochlorous acid. Mutagenesis 25: 149-154.

Hayat MJ, Howlader N, Reichman ME, Edwards BK (2007) Cancer statistics, trends, and multiple primary cancer analyses from the Surveillance, Epidemiology, and End Results (SEER) Program. Oncologist 12: 20-37.

Hong S, Kang YA, Cho BC, Kim DJ (2012) Elevated serum C-reactive protein as a prognostic marker in small cell lung cancer. Yonsei Med J 53: 111-117.

Houghton AM, Rzymkiewicz DM, Ji H, Gregory AD, Egea EE, Metz HE, Stolz DB, Land SR, Marconcini LA, Kliment CR, Jenkins KM, Beaulieu KA, Mouded M, Frank SJ, Wong KK, Shapiro SD (2010) Neutrophil elastase-mediated degradation of IRS-1 accelerates lung tumor growth. Nat Med 16: 219-223.

Keane MP, Belperio JA, Xue YY, Burdick MD, Strieter RM (2004) Depletion of CXCR2 inhibits tumor growth and angiogenesis in a murine model of lung cancer. J Immunol 172: 2853-2860.

Kim DK, Oh SY, Kwon HC, Lee S, Kwon KA, Kim BG, Kim SG, Kim SH, Jang JS, Kim MC, Kim KH, Han JY, Kim HJ (2009) Clinical significances of preoperative serum interleukin-6 and C-reactive protein level in operable gastric cancer. BMC Cancer 9: 155.

Kishi Y, Kopetz S, Chun YS, Palavecino M, Abdalla EK, Vauthey JN (2009) Blood neutrophil-to-lymphocyte ratio predicts survival in patients with colorectal liver metastases treated with systemic chemotherapy. Ann Surg Oncol 16: 614-622.

Kuang DM, Zhao Q, Wu Y, Peng C, Wang J, Xu Z, Yin XY, Zheng L (2011) Peritumoral neutrophils link inflammatory response to disease progression by fostering angiogenesis in hepatocellular carcinoma. J Hepatol 54: 948-955.

Kwon HC, Kim SH, Oh SY, Lee S, Lee JH, Choi HJ, Park KJ, Roh MS, Kim SG, Kim HJ (2012) Clinical significance of preoperative neutrophil-lymphocyte versus platelet-lymphocyte ratio in patients with operable colorectal cancer. Biomarkers 17: 216-222.

Lee S, Oh SY, Kim SH, Lee JH, Kim MC, Kim KH, Kim HJ (2013) Prognostic significance of neutrophil lymphocyte ratio and platelet lymphocyte ratio in advanced gastric cancer patients treated with FOLFOX chemotherapy. BMC Cancer 13: 350.

Li J, Jiang R, Liu WS, Liu Q, Xu M, Feng QS, Chen LZ, Bei JX, Chen MY, Zeng YX (2013) A large cohort study reveals the association of elevated peripheral blood lymphocyte-to-monocyte ratio with favorable prognosis in nasopharyngeal carcinoma. PLoS One 8: e83069.

Mantovani A, Allavena P, Sica A, Balkwill F (2008) Cancer-related inflammation. Nature 454: 436-444.

Murray N, Coy P, Pater JL, Hodson I, Arnold A, Zee BC, Payne D, Kostashuk EC, Evans WK, Dixon P, Sadura A, Feld R, Levitt M, Wierzbicki R, Ayoub J, Maroun JA, Wilson KS (1993) Importance of timing for thoracic irradiation in the combined modality treatment of limited-stage small-cell lung cancer. The National Cancer Institute of Canada Clinical Trials Group. J Clin Oncol 11: 336-344.

Nakamura T, Matsumine A, Matsubara T, Asanuma K, Uchida A, Sudo A (2013) The combined use of the neutrophil-lymphocyte ratio and C-reactive protein level as prognostic predictors in adult patients with soft tissue sarcoma. J Surg Oncol 108: 481-485.

Paesmans M, Sculier JP, Lecomte J, Thiriaux J, Libert P, Sergysels R, Bureau G, Dabouis G, Van Cutsem O, Mommen P, Ninane V, Klastersky J (2000) Prognostic factors for patients with small cell lung carcinoma: analysis of a series of 763 patients included in 4 consecutive prospective trials with a minimum follow-up of 5 years. Cancer 89: 523-533.

Pillay J, Kamp VM, van Hoffen E, Visser T, Tak T, Lammers JW, Ulfman LH, Leenen LP, Pickkers P, Koenderman L (2012) A subset of neutrophils in human systemic inflammation inhibits $\mathrm{T}$ cell responses through Mac-1. $J$ Clin Invest 122: 327-336.

Sagman U, Maki E, Evans WK, Warr D, Shepherd FA, Sculier JP, Haddad R, Payne D, Pringle JF, Yeoh JL (1991) Small-cell carcinoma of the lung: derivation of a prognostic staging system. J Clin Oncol 9: $1639-1649$.

Seifter EJ, Ihde DC (1988) Therapy of small cell lung cancer: a perspective on two decades of clinical research. Semin Oncol 15: 278-299.

Smith RA, Bosonnet L, Raraty M, Sutton R, Neoptolemos JP, Campbell F, Ghaneh P (2009) Preoperative platelet-lymphocyte ratio is an independent significant prognostic marker in resected pancreatic ductal adenocarcinoma. Am J Surg 197: 466-472. 
Spiegelman D, Maurer LH, Ware JH, Perry MC, Chahinian AP, Comis R, Eaton W, Zimmer B, Green M (1989) Prognostic factors in small-cell carcinoma of the lung: an analysis of 1,521 patients. J Clin Oncol 7: 344-354.

Stoppacciaro A, Melani C, Parenza M, Mastracchio A, Bassi C, Baroni C, Parmiani G, Colombo MP (1993) Regression of an established tumor genetically modified to release granulocyte colony-stimulating factor requires granulocyte- $\mathrm{T}$ cell cooperation and $\mathrm{T}$ cell-produced interferon gamma. J Exp Med 178: 151-161.

Stotz M, Gerger A, Eisner F, Szkandera J, Loibner H, Ress AL, Kornprat P, AlZoughbi W, Seggewies FS, Lackner C, Stojakovic T, Samonigg H, Hoefler G, Pichler M (2013) Increased neutrophil-lymphocyte ratio is a poor prognostic factor in patients with primary operable and inoperable pancreatic cancer. Br J Cancer 109: 416-421.

Stotz M, Pichler M, Absenger G, Szkandera J, Arminger F, Schaberl-Moser R, Samonigg H, Stojakovic T, Gerger A (2014) The preoperative lymphocyte to monocyte ratio predicts clinical outcome in patients with stage III colon cancer. Br J Cancer 110: 435-440.

Sun Z, Yang P (2004) Role of imbalance between neutrophil elastase and alpha 1-antitrypsin in cancer development and progression. Lancet Oncol 5: 182-190.
Szkandera J, Gerger A, Liegl-Atzwanger B, Absenger G, Stotz M, Friesenbichler J, Trajanoski S, Stojakovic T, Eberhard K, Leithner A, Pichler M (2013) The lymphocyte/monocyte ratio predicts poor clinical outcome and improves the predictive accuracy in patients with soft tissue sarcomas. Int J Cancer 135(2): 362-370.

Yalcinkaya E, Bugan B, Celik M, Yasar S, Gursoy E (2013) Neutrophil lymphocyte ratio should be assessed together with other inflammatory markers and confounding factors. Eur Rev Med Pharmacol Sci 17: 2410.

Yamanaka T, Matsumoto S, Teramukai S, Ishiwata R, Nagai Y, Fukushima M (2007) The baseline ratio of neutrophils to lymphocytes is associated with patient prognosis in advanced gastric cancer. Oncology 73: 215-220.

This work is published under the standard license to publish agreement. After 12 months the work will become freely available and the license terms will switch to a Creative Commons AttributionNonCommercial-Share Alike 3.0 Unported License. 